\title{
Family distribution of concomitant squint in Greece
}

\author{
E. CHIMONIDOU, G. PALIMERIS, J. KOLIOPOULOS, AND \\ P. VELISSAROPOULOS
}

From Athens University Eye Clinic

SUMMARY From a study of a large number of brothers and sisters suffering from concomitant squint, the following data were obtained: (1) $42.9 \%$ of the patients showed congenital strabismus. (2) In $96.5 \%$ of the sibs strabismus was of the same type. (3) The presence of a significant refractive error occurred in $82.8 \%$ of the patients. (4) In all twins strabismus appeared at the same age in both twins, and the squint and the refractive error were of the same type. (5) The distance of the patients' homes from Athens had no effect on either $(a)$ the time intervening between the onset of squint and the first visit to the eye specialist, or $(b)$ the effectiveness of treatment.

Investigations to determine the genetic element in strabismus and the type of heredity involved have been the subject of numerous studies (François, 1961; Richter, 1967), although no definite conclusions have so far been reached. The present study does not aspire to offer a solution to this complex question and confines itself to an examination of familial cases of squint with the purpose of extracting data concerning: (1) The age of onset of squint; (2) the type of squint; (3) the frequency of the existence of a significant refractive error; (4) the incidence of amblyopia; and (5) the geographical distribution of squint in relation to the place of residence and its influence on $(a)$ the period of time intervening between the onset of strabismus and the first ophthalmic consultation, and $(b)$ the efficacy of the treatment.

\section{Material and method}

Our material, drawn from the archives of the Orthoptic Department, which contains about 12000 patients, consists of 170 families containing 345 affected first degree relatives (brothers and sisters) who came under the observation of the Athens University Eye Clinic in the course of the last eight years. Cases of paretic strabismus or neurological syndromes were excluded from our study.

Information obtained from relatives suggested that the incidence of a family history of squint was $55 \%$. As we did not consider these data absolutely

Part of this paper was presented at the meeting of the International Geographical Society in Edinburgh, 1975.

Address for reprints: Dr E. Chimonidou, National Ophthalmological Center of Athens, 170 Messogion Avenue, Cholargos, Athens, Greece. reliable, we have included in our group of patients only those that were under observation and treatment for strabismus for a considerable length of time. Our patients included five pairs of twins (10 persons), one pair being uniovular.

The patients were subjected to examination for the following data: (1) Personal and family history; (2) visual acuity, and refractive error determined after the instillation of atropine for 3 days; (3) type and angle of squint; (4) state of binocular vision; (5) fundus of the eye and type of fixation; and (6) place of residence.

Furthermore, patients were treated appropriately in each instance by: (1) Prescription of glasses; (2) occlusion; (3) orthoptic treatment; (4) surgical treatment.

\section{Results}

\section{AGE OF ONSET OF SQUINT}

The onset of strabismus in the 345 patients occurred: (a) Within the first year of life (congenital strabismus) in 148 patients $(42.9 \%)$; $(b)$ after the first year of life in 197 patients $(57 \cdot 1 \%)$. Out of the 148 patients with congenital strabismus $62(42 \%)$ patients had a brother or sister affected with squint at a more advanced age, while the remaining 86 patients $(58 \%)$ were brothers or sisters whose strabismus deveoped at the same age (congenital). In this latter group were 38 families with two children (including three pairs of twins), two families with three children, and one family with four children suffering from squint.

Of the 197 persons in whom strabismus appeared after the first year of life $107(54 \cdot 3 \%)$ were brothers or sisters in whom the onset of squint differed by more than a year, while the remaining 90 persons 
$(45.7 \%)$ were brothers or sisters in whom the time difference in the development of squint was less than a year (among them two pairs of twins, one being uniovular). Thus out of the total number of 345 patients $176(51 \%)$ developed strabismus at the same time as their brother or sister.

It is interesting that strabismus in the uniovular twins developed at the age of 3 years, and that one of the children had been adopted when 3 months old by a well-to-do family.

\section{TYPE OF SQUINT}

The diagnosis of squint was made when one of the following was demonstrated by a cover test: (a) Manifest deviation; (b) exophoria over 9 $9 \Delta$; (c) esophoria over $7 \Delta ;(d)$ hyperphoria (including the alternating type). A convergent strabismus was found in 279 patients $(81.2 \%)$ and a divergent strabismus in 66 patients $(18.8 \%)$. Among the total, 12 had a sib showing a different type of squint-i.e., one sib had a convergent squint and the other a divergent one. The rest of the patients showed the same type of strabismus $(96.5 \%)$.

All the twins had a convergent squint; in three pairs of twins it was uniocular, involving the same eye in both sibs; in one instance it was of the alternating type in both sibs; and in one pair it was uniocular, involving the right eye in one sib and the left eye in the other.

\section{REFRACTIVE ERROR}

The refractive error was considered significant in all cases featuring: (a) Hypermetropia exceeding $3 \mathrm{D}$;

(b) myopia of any degree; (c) astigmatism over $\frac{1}{2} \mathrm{D}$; (d) anisometropia over $1 \mathrm{D}$.

On the strength of these criteria, a significant refractive error occurred in 285 patients $(82.8 \%$ of the total number). In the five pairs of twins, the refractive error was found to be similar in each sib.

\section{PRESENCE OF AMBLYOPIA}

In 173 of the patients $(50 \%)$ amblyopia was present at the first examination.

\section{GEOGRAPHICAL DISTRIBUTION}

The distribution of our patients with regard to their place of residence is shown in Table 1. In Greece there exist up-to-date orthoptic departments both in Athens and in Salonica, and thus our patients mainly come from the southern parts of the country.

To evaluate the effect of the distance of the patients' home from our orthoptic centre on their management we have taken into account two factors: (a) The time intervening between the onset of squint and the first ophthalmic consultation; and (b) the results obtained by occlusion in the treatment of amblyopia.
With regard to the time between the onset of strabismus and the first ophthalmic consultation by the patient, $49.8 \%$ of the patients (172 out of a total of 345) consulted an eye specialist within three years, and $23.48 \%$ of the patients (81 out of a total of 345) had their first consultation within one year of the onset of strabismus. From Tables 2 and 3 it will be seen that these percentages remain almost

Table 1 Geographical distribution of patients with regard to place of residence

\begin{tabular}{ll}
\hline Place of residence & $\begin{array}{l}\text { Number of } \\
\text { patients }\end{array}$ \\
\hline Nomos Attica (Greater Athens and Piraeus) & 154 \\
Mainland Greece (except Nomos Attica) & 29 \\
Epirus & 15 \\
Thessaly & 34 \\
Peloponnese & 50 \\
Euboea & 10 \\
Crete & 22 \\
Aegean Islands & 21 \\
Ionian Islands & 10 \\
\hline Total & 345 \\
\hline
\end{tabular}

Table 2 Geographical distribution of patients presenting themselves for the first examination within three years after the onset of squint

\begin{tabular}{lcl}
\hline & $\begin{array}{l}\text { Number of } \\
\text { patients }\end{array}$ & $\%$ \\
\hline $\begin{array}{l}\text { Nomose of residence } \\
\quad \text { Piraeus) }\end{array}$ & 78 & $50 \cdot 65$ \\
$\begin{array}{l}\text { Mainland Greece (except Nomos } \\
\quad \text { Attica) }\end{array}$ & 14 & $48 \cdot 28$ \\
Epirus & 7 & $46 \cdot 67$ \\
Thessaly & 17 & 50 \\
Peloponnese & 25 & 50 \\
Euboea & 5 & 50 \\
Crete & 11 & 50 \\
Aegean Islands & 10 & $47 \cdot 62$ \\
Ionian Islands & 5 & 5 \\
\hline Total & 172 & $49 \cdot 8 \%( \pm 1 \cdot 1)$ \\
\hline
\end{tabular}

Table 3 Geographical distribution of patients presenting themselves for the first examination within one year after the onset of squint

\begin{tabular}{lll}
\hline & $\begin{array}{l}\text { Number of } \\
\text { patients }\end{array}$ & $\%$ \\
\hline Place of residence & & \\
$\begin{array}{l}\text { Nomos Attica (Greater Athens and } \\
\quad \text { Piraeus) }\end{array}$ & 39 & 25 \\
Mainland Greece (Except Nomos & 7 & $24 \cdot 1$ \\
$\quad$ Attica) & 4 & $26 \cdot 7$ \\
Epirus & 8 & $23 \cdot 5$ \\
Thessaly & 13 & 26 \\
Peloponnese & 2 & 20 \\
Euboea & 6 & $27 \cdot 3$ \\
Crete & 5 & $23 \cdot 8$ \\
Aegean Islands & 2 & 20 \\
Ionian Islands & & \\
\hline Total & 81 & $23 \cdot 48 \%( \pm 3 \cdot 7)$ \\
\hline
\end{tabular}


Table 4

\begin{tabular}{|c|c|c|c|c|c|c|c|}
\hline \multirow{3}{*}{ Place of residence } & \multirow{3}{*}{$\begin{array}{l}\text { Number of } \\
\text { cases of } \\
\text { amblyopia }\end{array}$} & \multicolumn{6}{|c|}{ Results of treatment } \\
\hline & & \multicolumn{2}{|c|}{ Visual acutity $10 / 10$} & \multicolumn{2}{|c|}{ Visual acuity $7 / 10-9 / 10$} & \multicolumn{2}{|c|}{ Visual acuity $<7 / 10$} \\
\hline & & Patients & $\%$ & Patients & $\%$ & Patients & $\%$ \\
\hline $\begin{array}{l}\text { Nomos Attica (Greater Athens/ } \\
\text { Piraeus) } \\
\text { Mainland Greece (except Nomos }\end{array}$ & 77 & 46 & $59 \cdot 7$ & 12 & $15 \cdot 6$ & 19 & $24 \cdot 7$ \\
\hline Attica) & 15 & 9 & 60 & 2 & $13 \cdot 3$ & 4 & $26 \cdot 7$ \\
\hline Epirus & 7 & 4 & $57 \cdot 1$ & $i$ & $14 \cdot 3$ & 2 & $28 \cdot 6$ \\
\hline Thessaly & 17 & 10 & $58 \cdot 8$ & 3 & $17 \cdot 7$ & 4 & $23 \cdot 5$ \\
\hline Peloponnese & 25 & 15 & 60 & 4 & 16 & 6 & 24 \\
\hline Euboea & 4 & 2 & 50 & $i$ & 25 & 1 & 25 \\
\hline Crete & 12 & 7 & $58 \cdot 3$ & 2 & $16 \cdot 7$ & 3 & 25 \\
\hline Aegean Islands & 12 & 7 & $58 \cdot 3$ & 2 & $16 \cdot 7$ & 3 & 25 \\
\hline Ionian Islands & 4 & 2 & 50 & 1 & 25 & 1 & 25 \\
\hline Total & 173 & 102 & $59 \%( \pm 5 \cdot 7)$ & 28 & $16 \cdot 2 \%( \pm 6$ & 43 & $24.8 \%$ \\
\hline
\end{tabular}

constant irrespective of the place of residence of the patients.

With regard to the results of treating amblyopia by occlusion, it was ascertained that out of a total number of 173 patients: a visual acuity of $10 / 10$ was obtained in 102 patients $(59 \%)$; a visual acuity between $7 / 10$ and $9 / 10$ was obtained in 28 patients $(16.2 \%)$; and a visual acuity of less than $7 / 10$ was obtained in 43 patients $(24.8 \%)$. Table 4 shows that these percentages remain more or less constant regardless of the distance of the patients' domicile from hospital.

\section{Comment}

The question whether squint is a genetically determined disorder has been much discussed. Richter (1967) states that the two types of hereditary transmission, autosomal dominant and autosomal recessive, are insufficient to explain the hereditary transmission of strabismus. Vogel and Krüger (1967) considered that strabismus is inherited in a multifactoria! manner.

We believe that our study, based as it is on material with a marked family distribution, supports the hereditary nature of strabismus. $42.9 \%$ of the cases of squint were congenital, $51 \%$ of the patients developed strabismus at the same age as their brother or sister, and $96.5 \%$ of the brothers and sisters suffering from squint showed strabismus of the same type. In twins strabismus occurred at the same age in each sib.

The case of uniovular twins who both developed a squint at the age of 3 years in spite of growing up in different family environments from a very early age supports the view of Graham (1974) that environment has no effect on the occurrence of strabismus.

Pratt-Johnson and Lunn (1967) found a significant refractive error in $62 \%$ of their patients, as compared with $82.8 \%$ in our series. This high incidence of refractive errors probably occurred because our series consisted exclusively of brothers and sisters and thus emphasises both the hereditary nature of refractive errors and their connection with the occurrence of strabismus.

The geographical distribution of our material shows that the distance of the patient's home from Athens does not affect either the time intervening between the onset of squint and the first ophthalmic consultation, or the effectiveness of subsequent treatment.

We recommend to all parents that their other children should be examined once a squint has occurred in one child of the family.

The authors thank the orthoptist, Miss E. Koulopoulou, for her valuable assistance in the collection and processing of the material.

\section{References}

François, J. (1961). 'Heredity in Ophthalmology'. St. Louis, Mosby.

Graham, P. A. (1974). British Journal of Ophthalmology, 58, 224.

Pratt-Johnson, J. A., and Lunn, C. T. (1967). Canadian Journal of Ophthalmology, 2, 50.

Richter, S. (1967). Untersuchungen über die Heredität des Strabismus concomitans. Monographien. Berlin, Edition Leipzig.

Vogel, F., and Krüger, J. (1967). Multifactorial determination of genetic affections. In J. F. Crow and J. V. Neel (eds.), Proceedings of the Third International Congress of Human Genetics, pp. 437-445. Baltimore, Johns Hopkins Press. 